\title{
Update to the Probabilistic Volcanic Hazard Analysis, Yucca Mountain, Nevada
}

Coppersmith, K.J., Coppersmith Consulting, Inc., 2121 N. California Blvd, \#290, Walnut Creek, CA; Jenni, K., Nieman, T., Perman, R.C., Youngs, R.R., Geomatrix Consultants, Inc., 2101 Webster St., Oakland, CA 94612; Perry, F., Los Alamos National Laboratory, P.O. Box 1633, Los Alamos, NM 87545; Cline, M., Bechtel SAIC LLC, 1180 N. Town Center Drive, Las Vegas, NV 89144

A probabilistic volcanic hazard analysis (PVHA) was conducted in 1996 for the proposed repository at.Yucca Mountain, Nevada. Based on data gathered by the Yucca Mountain Project over the course of about 15 years, the analysis integrated the judgments of a panel of ten volcanic experts using methods of formal expert elicitation. PVHA resulted in a probability distribution of the annual frequency of a dike intersecting the repository, which ranges from $10 \mathrm{E}-7$ to $10 \mathrm{E}-10$ (mean $1.6 \times 10 \mathrm{E}-8$ ). The analysis incorporates assessments of the future locations, rates, and types of volcanic dikes that could intersect the repository, which lies about $300 \mathrm{~m}$ below the surface. A particular focus of the analysis is the quantification of uncertainties. Since the 1996 PVHA, additional aeromagnetic data have been collected in the Yucca Mountain region, including a highresolution low-altitude survey. A number of anomalies have been identified within alluvial areas and modeling suggests that some of these may represent buried eruptive centers (basaltic cinder cones). A program is currently underway to drill several of the anomalies to gain information on their origin and, if basalt, their age and composition.

To update the PVHA in light of the new aeromagnetic and drilling data as well as other advancements in volcanic hazard modeling over the past decade, the expert panel has been reconvened and the expert elicitation process has been fully restarted. The analysis requires assessments of the spatial distribution of igneous events, temporal distributions, and geometries and characteristics of future events (both intrusive and extrusive). The assessments are for future time periods of 10,000 years and 1,000,000 years. Uncertainties are being quantified in both the conceptual models that define these elements as well as in the parameters for the models. The expert elicitation process is centered around a series of workshops that focus on the available data; alternative approaches to modeling spatial, temporal, and event definitions; preliminary assessments of model and parameter values; and feedback. Discussions and interactions among the experts are strongly encouraged and they are charged with considering the views of the larger technical community. Expert judgments are elicited in individual interviews and the technical basis for all assessments is documented. The results of the PVHA Update will be a series of probability distributions defining the annual frequency of various types of igneous events that could disrupt the repository. These distributions will be used as input to the total system performance assessment of the repository system. 